TRAUMATIC SEPARATION OF THE LOWER EPIPHYSIS OF THE HUMERUS WITH DISPLACEMENT FORWARDS.

BY W. MCADAM ECCLES, M.S. LoxD., F.R.C.S. ENG., ASSISTANT SURGEOX. WEST LONDON HOSPITAL, CITY OF LONDOX IRESS SOCIETY, DWMOTSTRATOR OF UPERATTYF SURGERY AT S'P. BARTHOLOMEW'S HUSPITAL, ETC.

THE rarity of displacement forrarls after separation of the lower epiphysis of the humerus induces me to put on record the following case.

A boy, aged ten years, living in the country fell, as I understand, from a see-saw, or swing, alighting on his right hand. Shortly afterwards the elbow was painful, but as there was no idea of any serious injury having occurred medical advice was not sought until some time had elapsed and no splint was applied. At the end of three weeks, as the elbow remained stiff and slightly swollen, the patient was brought up to town. The right forearm was in a position of flexion, forming an angle of $145^{\circ}$ with the arm, and the boy was unable to extend it roluntarily any further. Full flexion, however, could be satisfactorily accomplished and practically without discomfort. The biceps cubiti was kept contracted. The forearm, moreover, was somewhat pronated and it was impossible for the patient by his own effort to completely supinate without pain. Examination under ether showed flexion to be free, but extension impeded though it could be forcibly accomplished. Creaking about the joint was noticed, but all the usual movements were nearly normal in their range. When I saw him first in consultation with Dr. John ShawMackenzie between four and five weeks after the original injury, it was observable that there was no evidence of inflammation about the joint. A distinct dimple could be seen about the tip of the olecranon process, which was not apparent on the sound side. The three bony prominences bore their normal relationship to one another, but appeared to be on a plane anterior to the shaft of the humerus when compared with the left side. Measurement of the arm gave a like length on the two sides, but the distance from the projecting part of the humerus on the outer side to the radial styloid process showed some increase in the length of the forearm. Forcible movement without an anæsthetic proved that full extension of the elbow joint was impossible, though flexion could be readily brought about. The other points were much the same as those alluded to above. Seeing the unusual nature and uncertainty of the lesion my friend, Dr. F. H. Low, very kindly and successfully skiagraphed both the normal and abnormal elbow-joints. Each limb was placed with its inner surface upon the sensitive plate, with the elbow flexed at a right angle. The prints from the negatives showed rery clearly the dimple mentioned before in the curve of the line of the soft parts. It showed, further, that the brearth of the limb at the region of the elbow was distinctly increased, and this without there being any local swelling or cedema. The ossific centres of the lower epiphysis were displaced distinctly forwards, well shown by their relationship to the shaft of the humerus.

I have been unable to find more than a few references to what I believe the case under review to be-namely, a traumatic separation of the lower epipbysis of the humerus with displacement forwards Hamilton ${ }^{1}$ does not mention it and Pick $^{2}$ makes no allusion to it, nor does R. W. Smith ${ }^{3}$ in his paper on the subject. All these and other authorities give a full account of the much more common backerard displacement. An excellent skiagram of this latter deformity is given by Roswell Park. ${ }^{4}$ J. Hutchinson. jun., says ${ }^{5}$ : "Yery occasionally the epiphysis is driven forwards instead of backwards," and in one case under his care the forward displacement was well marked. I believe the prognosis as to the subsequent growth and usefulness of the limb is good in the majority of these cases, provided that passive movement, together with massage, is early resorted to. In this

1 A Treatise on Fractures and Dislocations, eighth edition. Fractures and Dislocations, 1890, p. 191

3 Dublin Quarterly Journal, vol. ix., 1850, p. 63, and Brit. Med. Jour., vol. ii., 1867, p. 121 .

5 Brit. Med. Jour., vol. ij., 1E93, p. 1418 . particular case the patient has now a useful limb, with bus little deformity, although it has taken many months to bring this result about

Harley-street, $W$.

\section{CHLORODYNE POISONING}

\section{By JAMES GILROY, M.B., C.M. GLASG.}

ON Jan. 15th, 1895, at 12.30 A.M., I was called to see a $\operatorname{man}_{x}$ aged seventy years. Having to travel two miles I did not see him till 1 A.M. I found him unconscious with stertorous breathing and the pupils unequal, the left being contracted to a pin's point and the right moderately dilated. The surface of the body was fairly warm, there was a considerable amount of perspiration over the trunk, and the pulse was full and regular, being about 70 per minute. The history I got was that about 8.30 P.M. on the 14 th he had retired to bed as was his wont and that later, about 11 P.M., some of his family fancied they heard unusually heavy breathing and entered his room, having to force the door, and found the patient on the floor; lying in close proximity was a bottle of cough mixture, an eight-ounce bottle, which was tbree-quarters empty, leaving scarcely? two ounces in the bottle. The mixture smelt strongly of chlorodyne and was a patent medicine labelled "Joe Todd and Co.," with a graduated dose scale given on the label up to one tablespoonful and "not intended for infants" printed thereon, together with an intimation on the reverse side that "owing to containing morphine and other valuable drugs" the requirements of the law required it to be labelled "poison." I was told that before I had arrived the patient had romited slightly, his son having administered mustard and water and put him to bed. Not having hads any intimation of the nature of the case I had nothing: with me, but despatched a messenger for the stomach tube and some emetics and meanwhile I proceedec to try to rouse the patient, which was apparently indicated. This was done by pinching him, signs of pain being evinced, and by getting him out of bed and walking: him about as best we could for upwards of an hour. He exhibited signs of knowing what was being done, but his condition was, to say the least, alarming. On arrival of the tube I washed out the stomach freely with hot water and followed by introducing some infusion of green tea and later some Liebig's extract in hot water. About 5 A.M. I left him, after having expended some considerable effort and finding that on speaking loudly to him he evinced signs of consciousness. I called again at 4 P.M. I found hims still sleeping soundly, the pupils being in the same condition as before; there was no change. I introducec s into the stomach two-thirds of a quart of warmed milk. with a little lime-water, and left him, to return again at midnight to find the same state of affairs, wher I again introduced about one pint of milk with the stomach tube. I continued to attend the patient twice: daily all the week and the treatment was as stated all through until the afternoon of the 18th, when he awoke and sat up to assist me with the tube, which he appeared quite to understand was being used for his benefit, but he did not speak, though when he was spoken to his lips moreck as if he were attempting to answer. On the 16th I noticed the odour of opium very perceptibly in his breath, but on no. other day could I detect it except more faintly on the 17th. On the 19th, on my visiting him in the afternoon, he spoke to me quite plainly, asking if he had been asleep over twenty minutes. Ajl through there was no involuntary discharge of urine. It was passed naturally and was loaded with urates, and only on one day-viz., the 17th-was it retained over twenty-four hours.

The patient told me that the dilated eye had been one for. which he had had special advice and treatment, but whether that had anything to do with the inequality of the pupils is, another question; but $I$ noted that the condition was still present on the 23rd-that is to say, although the firm contraction had yielded in one eve the other pupil was larger. He was then taking his food well and was very hungry. On the 19th the history I got was that his demands for food were incessant, whilst on the 23rd he had practically recovered. The mixture came into his possession on the evening of the 12th and he simply drank it ad libitum at intervals, and admitted taking a drink of it from the bottle 